\title{
Computers, psychology, and work: Does the past predict a troubled future for this union?
}

\author{
DONALD I. TEPAS \\ University of Connecticut, Storrs, Connecticut
}

\begin{abstract}
The innovations of the industrial revolution often led to dull jobs that were mindless, boring, monotonous, and/or fatiguing. I propose here that the misapplication of computer systems in the current technological revolution is also leading us to dull jobs. This is not appropriate, since there is reason to believe that skilled and empowered workers are more cost-effective. These misapplications of computer systems must be avoided.
\end{abstract}

In my 1971 introductory remarks to the first meeting of what we now call the Society for Computers in Psychology, I was full of excitement and optimism with regard to developments in the computer industry and their application by psychologists. At that meeting, I noted (Tepas, 1972) that computer systems with $4 \mathrm{~K}$ of memory would soon be available off-the-shelf with a price of less than $\$ 4,000$. Desk-drawer-sized central processing units (CPUs) were a reality, and a nationwide microwave network was in the planning stage! Today, faster computer systems with $2 \mathrm{MB}$ of memory plus a $40-\mathrm{MB}$ hard disk are available for less than $\$ 1,000$. CPUs the size of a human fingernail are common, and satellite relay stations in outer space are replacing microwave networks.

I continue to be excited by the hardware developments in the computer industry, but I am no longer an optimist about how these developments are being applied by psychologists. In 1971 , nearly everyone expected very significant decreases in the cost of computers and increases in their hardware capabilities. By today's standards, however, most of us were much too conservative and naive in our optimistic hardware and price projections for the future. Today, looking 20 years into the future, I am confident that most of us would continue to predict another large decrease in the cost of computers and another quantum increase in hardware capabilities. This time, however, one is reluctant to make specific predictions. Even our wildest dreams will probably prove to be much too conservative.

So, why am I no longer optimistic about how these amazing hardware and software developments will be used by psychologists? After all, it is undoubtedly true that more psychologists than ever before are now using computers, and these numbers are bound to increase as new professionals enter the field. My lack of optimism is based on how I now find psychologists using computers. I fear that some very important workplace problems and issues,

Correspondence should be addressed to Donald I. Tepas, Ergonomics Laboratory, Department of Psychology, 406 Babbidge Road, Box U-20, University of Connecticut, Storrs, CT 06269-1020. identified well before the first electronic computer was built, will be ignored.

\section{Some Society Social History}

The first Steering Committee of the Society was not elected, it was hand-picked by me. I sent letters of invitation to people, and everyone accepted, without any armtwisting! By design, I invited individuals who seemed to represent the diverse (in specialty, geographical area, institutional type, and age) group of psychologists who were already using dedicated computers. These individuals had two common characteristics: they were using computers in their research; and, they were interested in sharing and promoting the use of computers in psychology.

These were the people who came up with the idea of having regular meetings and forming the Society. Most of them served on the Steering Committee for 3 or more years, generated a constitution for the Society, and contributed in a variety of ways to ensure a self-sustaining organization. Without exception, they thought of themselves as being primarily research scientists, not computer specialists, hackers, or groupies. Although they were associated with academic institutions, there was very little talk about using computers as undergraduate teaching aids.

A survey of those who attended the first conference (Tepas, 1974b) also supports the notion that these pioneers were interested in using computer systems for research purposes. For example, less than 3\% of the respondents with dedicated computer systems indicated that they were using their systems as teaching machines or for computeraided instruction. Most systems in use were idiosyncratic hardware combinations dedicated to the research needs of specific users. In general, it also seems fair to surmise that most users were interested in computer techniques that would allow them to manipulate, detect, and measure things in their research that were not feasible or practical without a computer. My presidential address at the third meeting provides an example of this (Tepas, 1974a).

It is my impression that in subsequent years the meetings of the Society changed. The meetings now include many presentations directed toward the use of computers in undergraduate instruction. There are serious and sus- 
tained efforts directed toward creating and disseminating widely applicable and flexible psychology laboratory software. Investigators also report on "intelligent" software, aimed at the development of "smart" systems that may be easier to use. Active and overt participation in the meetings by the computer industry itself seems to be minimal, discrete, and sometimes disguised.

These apparent changes in the Society are probably related to a number of factors. Obviously, the decrease in hardware prices increases the number of psychologists able to use dedicated computer systems. Decreases in cost of computer memory and increases in computing machine features result in low-cost systems with tremendous power and a practical networking capacity. At the same time, there is an evolving interest in finding modern ways to upgrade truly archaic undergraduate psychology laboratory instructional methods. Changes in policy by the Society, as well as changes in computer marketplace economics, have decreased direct computer industry support and participation in our meetings. This is a different Society.

\section{Psychology and the Computer Industry}

At present, the public, the psychologists, and the computer industry have a strange relationship. Many psychologists are eager consumers of computer technology, but the computer industry does not see psychology as an attractive major market area. At the same time, the computer industry and related technology are consuming the services of psychologists at a high rate. Many of those who provide these services are not active participants in the traditional psychological associations. Although the outcomes of these developments in the technological revolution are affecting the public, most people do not as yet associate them with the science of psychology.

The popular public media (Rogers, 1991) and psychology (Norman, 1988) critics often provide their readers with entertaining examples of how the products of the computer industry and the current technological revolution are failing us. A cursory reading of such publications can leave the reader with the impression that the computer industry and psychologists lack all concern about these problems. But this would be an inaccurate impression, even though it is shared by many people. Moreover, such accounts fail to recognize major changes that have occurred within the computer industry and related groups of professionals during the past 10 years.

For example, over 2,000 professionals attended a recent meeting of the Association for Computing Machinery Special Interest Group for Computer-Human Interaction (Silva, 1990). The Human Factors Society (HFS) provides further evidence of these changes. The HFS is only about 35 years old, and it has over 4,500 members; but the membership has increased significantly over the past 10 years. Around one half of the HFS members have psychology degrees, and about $25 \%$ of the members are employed by the computer industry. Given that not everyone in the human factors/ergonomics area belongs to the
HFS, one can estimate that there are now over 9,000 human factors specialists in the United States (see Education and Utilization, 1990). One major American computer manufacturer alone employs over 500 human factors specialists at a variety of sites and applications.

What are these people doing?-I suspect that the readers of this paper already have at least a modest idea. A detailed and descriptive catalogue of their activities is obviously beyond the scope of this paper. The naive reader will find a fairly good survey of these activities in Nickerson (1986). A representative, though incomplete, listing would include terms, ideas, or concepts such as the following: software usability testing, artificial intelligence research and development, expert systems, knowledge machines, computer-aided design, knowledge acquisition systems, graphic interfaces, and so forth.

At the risk of oversimplification and criticism, let me suggest that all these activities have at least one major factor in common: they are attempts to develop "smarter" computer systems - that is, they represent efforts aimed at designing systems that use computer power to make work easier, more reliable and valid, and/or more comfortable. It also seems clear that the major reason why the computer industry is interested in developing most of these systems is the growing realization that "smart" systems leave good introductory impressions and thereby sell hardware. Any potential problems connected with longterm use are ignored.

\section{Psychology and Work}

Industrial psychology has a long and colorful history of looking at the problems of people at work. It is a child of the industrial revolution, born at the very beginning of the 20th century. The industrial revolution resulted from a number of innovations in "hardware." These innovations led to the creation of factories and to large-scale machine production. These developments in turn led to major changes in social and economic structure. Although historians debate when these phenomenal changes started, it is clear that factory methods were in place for decades before industrial psychology as a professional specialization was born. During those decades, factories grew and operational complexity increased. Market competition also increased, which led managers to seek ways to decrease factory waste and inefficiency.

It is not surprising that, owing to their eagerness to increase worker productivity at the turn of the century, many managers adopted some of the ideas and concepts of the engineer Frederick Winslow Taylor. Starting in 1882, Taylor developed the controversial multidimensional approach that became known as "scientific management" (SM). Taylor discerned the importance of certain progressive concepts, which included the importance of paying workers good wages, joint worker-employer task and goal setting, and the need for long-term worker job training and development (Taylor, 1947). In practice, however, many employers (and probably Taylor himself) elected to adopt SM in a selective manner. 
The most frequent result was a combination of preTaylor management systems and Taylor's new philosophy. This amalgam often included the following concepts: There is a single best way to accomplish any workplace task. The labor force is usually lazy and underworked, and it has little to contribute to job design. Workers can be viewed mainly as appendages to machines. Jobs should be designed so that they require less worker skill and little decision-making. Reducing laborers' thoughts and actions is a cost-effective approach.

The usual result was jobs that were mindless, dull, boring, monotonous, and sometimes fatiguing. To be fair, it should be recognized that this was probably not what Taylor himself had in mind. It is, however, what the industrial revolution led to in most American industrial workplaces. For years, most industrial psychologists have been working hard in practical ways to try to overcome this approach to the workplace. Unfortunately, much of organized labor, as well as the individual workers themselves, has failed to this day to recognize what psychology was trying to do. For most people, work is no longer enjoyable, and psychology is viewed as one of the sources of this alienation.

\section{Computers and Work}

In the last 30 years, dramatic changes have occurred in how work is done in many overseas industrialized countries and a few American workplaces. Sweden, Germany, Japan, and other countries have demonstrated that empowering workers and increasing their skills can increase productivity and be cost-effective (Osterman, 1989). Unfortunately, most of the computer activities in which psychology is now heavily invested (software usability testing, artificial intelligence, expert systems, knowledge machines, computer-aided manufacturing, etc.) are mainly aimed at reducing the skill required of workers, and they often limit the degree to which workers are empowered to control the processes. Already, the result frequently consists of jobs that are mindless, dull, boring, monotonous, and sometimes harmful.

One does not have to search long to find computerrelated jobs in which this is the case. For example, people are employed for hours at video display terminals doing jobs "aided" by sophisticated computer software. Millions of dollars are now being spent to develop more "advanced" systems that are intended to ensure adequate use by users with minimum skill. Many managers are using computer systems that increase their ability to monitor worker behavior, giving them even more power over their employees. Work hours are often increased or become more unpredictable to allow the efficient operation of a computer-controlled process or system. That is, the computer system-not the worker or the manager-drives work hours. As a result, negative workplace attitudes are becoming more common in computer-driven jobs, owing to the underutilization of workers, monotonous duties, fear of job loss, and/or frequent shortages of trained technical staff.
Taylor's philosophy and the amalgam SM were honest attempts to increase the productivity of the industrial revolution. Experience, together with overseas workplace innovation, has shown that they were not a long-term solution to the problems of the industrial revolution. They are not a solution for the technological revolution, either. The approach of much of psychology toward computers and the technological revolution seems to parallel what happened with the industrial revolution. Once again, efforts are being aimed at reducing the need for worker skill and at minimizing worker empowerment. It would seem that history may be repeating itself, by following a model of what the workplace should be that in the long run will lead to the degradation of work and to decreases in productivity.

During the last part of the industrial revolution, psychology tried to restrain and modify these trends. I fear that this time the involvement of psychology with computers is at the early part of an era, and that it often seems to be leading industry and the technological revolution in the wrong direction. During the industrial revolution, psychology was falsely blamed for what it did not do. Given the assumption that misapplication of the computer will turn out to be a major characteristic of the current technological revolution, it may very well be that this time psychology will be properly blamed for this condition.

\section{The Misapplication Hypothesis}

In general, what I am proposing is that the misapplication of computers decreases productivity. A hallmark of the current technological revolution is the use of computers. This is a key and appropriate development. As the technological revolution continues, not only are computers going to be used more, the computer systems themselves will become "smarter." I propose that the current trend is for productivity to decrease as computer system "smartness" increases. Figure 1 provides an example of one way in which this hypothesis might manifest itself. The hypothetical function in this figure proposes that the cost of workplace-related injury, illness, and error increases as computer system "smartness" increases.

To date, very little empirical data support this misapplication hypothesis directly. There is, however, a growing concern in the public media that is sympathetic with this hypothesis (Kilborn, 1990), and there is a longstanding human factors concern with the issue of allocation of function (Kantowitz \& Sorkin, 1987). For the reader willing to make a large number of questionable assumptions, Figure 2 provides some modest initial support for the hypothesis. The data plotted in this figure represent the incidence rates of workdays lost to occupational injury and illness per 100 full-time workers per year for 1973-1989. These data are reported by the United States Department of Labor's Bureau of Labor Statistics and are based on responses to their survey of employer records of job-related injuries and illness (USDL, 1990). The straight line fit to the data in Figure 2 might be interpreted as suggesting that there has been an increase in the incidence rate of lost workdays during a time when 
computer applications and "smartness" have been increasing at a high rate. It also covers the lifetime of the Society for Computers in Psychology.

Obviously, this is not a definitive finding with regard to the misapplication hypothesis. It is certainly not a suggestion that computer use should be restrained. At the very least, however, one must conclude that it does not support the hypothesis that computer use increases productivity. It may be a first sign that the misapplication hypothesis has some validity, and that the current approach to workplace computer applications requires more scrutiny.

\section{What Is Needed?}

Smith (1989) has suggested that the problem of misapplication of computer technology may be the greatest challenge of the technological revolution. To paraphrase Ilmarinen (cited in Brunila, 1990), people still want to work, but the work has to be made interesting, because work has already lost the battle with leisure. Obviously, responses to the proposal made in this paper could follow any one of a number of lines. In the following paragraphs, I will outline a few themes, those which seem most appropriate to me for the members of the Society for Computers in Psychology to consider in the future.

From the beginning, the Society has had many "show and tell" presentations; that is, people tell about their new hardware and software systems. In only a few of these papers and presentations have the authors bothered to present empirical data showing that these methods work better in practice than previous methods or systems do. Even more important is that there have been virtually no presentations at these meetings showing the longitudinal impact of computer-based educational systems. Laboratories are workplaces. One might ask if the introduction of psychology software systems to the undergraduate laboratory has in fact increased performance on the Graduate Record Exam, changed departmental operating expenses, or improved student interest. I suspect that the

PROPOSED RELATIONSHIP BETWEEN SYSTEM SMARTNESS AND THE COST OF INJURY, ILLNESS AND ERROR

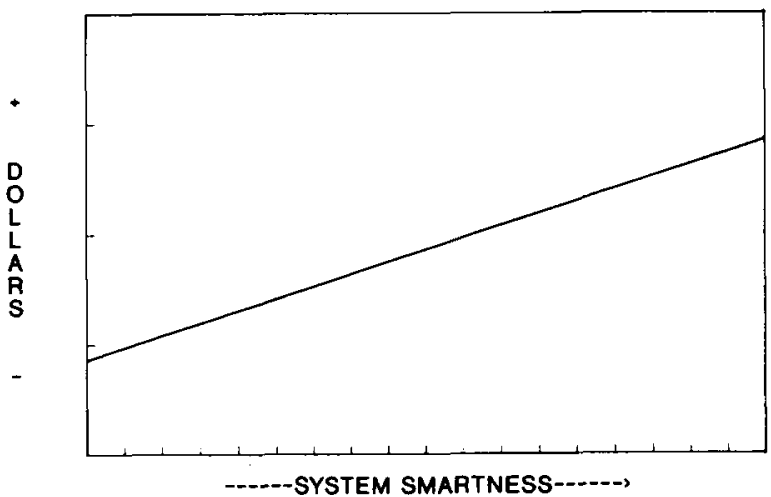

Figure 1. Proposed relationship between computer system "smartness" and the cost of injury, illness, and error.
LOST WORKDAYS - U.S.A. 1973-1989

OCCUPATIONAL INJURY \& ILLNESS INCIDENCE

RATES PER 100 FULL-TIME WORKERS

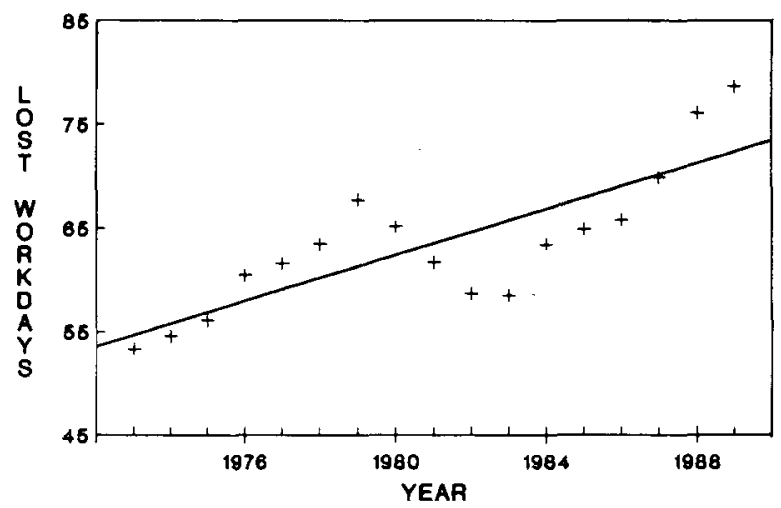

Figure 2. Occupational injury and illness incidence rates for lost workdays in the United States for 1973-1989. The incidence rates represent the number of lost workdays per 100 full-time workers. (Data from USDL, 1990.)

founders of the Society would be pleased to see research findings of this sort added to Society paper presentations.

Most software usability laboratories are located within the computer industry. Although these laboratories are quite active and involve a significant corporate investment in equipment and staff, most scientists would judge the actual methods that they use as being quite primitive. Much of the analysis is qualitative, and nearly all of it focuses on the problems associated with the initial use of a specific existing or proposed software package, not long-term use. This sells software, but overlooks any problems that might be associated with long-term use. Usability psychologists in industry often complain that academic scientists do not study problems of interest to them. An effort might be made to lure these people to Society so that we can become more sensitive to their problems and to the research that is needed. Industry might be asked to provide awards for the best usability research papers presented at the meetings. Government agencies might be asked to fund the establishment of independent academic-institution-based software usability evaluation and research laboratories molded to be compatible with those in industry.

Although government laboratories (see, e.g., Henning, Sauter, Salvendy, \& Krieg, 1989; Rosa, Colligan, \& Lewis, 1989) have attended to "state" variables such as fatigue and stress, neither industry nor academic research has focused on these important practical dimensions of computer use. We have only a modest knowledge of the psychological variables associated with using computers over long periods of time, and research in this area should be encouraged and driven by investigators who are independent and free of industry ties. In addition, a basic issue remains to be examined in a comprehensive way: Can computer software itself be written or designed to manipulate state variables in either a negative or a positive direction? 
Finally, one might simply ask some questions about the task of writing computer programs. Anyone who has ever written a program that runs remembers quite well the excitement associated with that experience. This positive response soon disappears for most people. After a few programs, one seeks others to do the task, if at all possible. One sometimes gets the impression that many people learn new programming languages simply to recapture the excitement of mastering the writing task! Clearly, some programming languages and interfaces are easier and more interesting than others. But where is the empirical data or theory to support these impressions? There are painfully few benchmarks for evaluating the quantity and quality of programming, let alone studies of how programming (language, interface, etc.) quantity and quality interact with the programmer's quality of life.

If the past is prologue, we may be in trouble. The introduction of new methods during the industrial revolution led to a dull workplace strewn with injury, illness, and error. We are now in the midst of another revolution, one in which the computer seems to be leading us in the same direction as our last failure did. Psychology can change this projected outcome if it elects to move in some new directions. "Smart" computer systems are resulting in major social and economic changes that we no longer can ignore.

This Society was founded by active research scientists. Some of them are no longer with us. I do expect that they would all be pleased to see that the Society is alive with a membership that is attempting to respond to old problems with new methods, goals, and research.

\section{REFERENCES}

Brunila, M. (1990). There is a working life after 50. In Work health safety (TTT) (pp. 23-25). Helsinki, Finland: Institute of Occupational Health.
Education and utilization of human factors specialists: Results of a survey (1990). Panel at the 34th Annual Meeting of the Human Factors Society, Orlando, FL.

Henning, R. A., Sauter, S. L., Salvendy, G., \& Krueg, E. F., Jr, (1989). Microbreak length, performance, and stress in a data entry task. Ergonomics, 32, 855-864.

Kantowitz, B. H., Sorkin, R. D. (1987). Allocation of functions. In G. Salvendy (Ed.), Handbook of human factors (pp. 355-369). New York: Wiley.

KILBORN, P. T. (1990, December 23). Workers using computers find a supervisor inside. The New York Times, p. 1.

NICKERSON, R. S. (1986). Using computers: The human factors of information systems. Cambridge, MA: MIT Press.

Norman, D. A. (1988). The psychology of everyday things. New York: Basic Books.

OSTERMAN, P. (1989). New technology and the organization of work: A review of the issues. In D. C. Mowery \& B. E. Henderson (Eds.), The challenge of new technology to labor-management relations (BLMR Publication No. 135, pp. 5-13). Washington, DC: U.S. Government Printing Office.

Rogers, M. (1991, January 7). The right button. Newsweek, pp. 46-47.

Rosa, R. R., Colligan, M. J., LEWIS, P. (1989). Extended workdays: Effects of 8-hour and 12-hour rotating shift schedules on performance, subjective alertness, sleep patterns, and psychosocial variables. Work \& Stress, 3, 21-32.

Silva, C. (1990, August 15). Back to the lab. Datamation, pp. 57-59.

SмITH, M. J. (1989). New technology, health and safety, and labormanagement relations. In D. C. Mowery \& B. E. Henderson (Eds.), The challenge of new technology to labor-management relations (BLMR Publication No. 135, pp. 17-29). Washington, DC: U.S. Govemment Printing Office.

TAYLOR, F. W. (1947). Scientific management [comprising Shop Management; The principles of scientific management; Testimony before the Special House Committee]. New York: Harper.

TEPAS, D. I. (1972). Introductory remarks. Behavior Research Methods \& Instrumentation, 4, 42-43.

TEPAS, D. I. (1974a). Computer analysis of the electroencephalogram: Evoking, promoting, and provoking. Behavior Research Methods \& Instrumentation, 6, 95-110.

TEPAS, D. I. (1974b). Computer use in the psychology laboratory: A survey. Computer Programs in Biomedicine, 4, 53-58.

U.S. Department of Labor, Bureau of Labor Statistics (1990). (BLS Reports on Survey of Occupational Injuries and Illnesses in 1989). News (USDL Publication No. 90-582). Washington, DC: U.S. Government Printing Office. 